\title{
As políticas científicas na era do conhecimento: uma análise de conjuntura sobre o ecossistema científico global
}

\author{
Thaiane Oliveira ${ }^{I}$ \\ IUniversidade Federal Fluminense, Rio de Janeiro, RJ, Brasil. \\ Professora do Programa de Pós-graduação em Comunicação. \\ Coordenadora do Fórum de Periódicos e Comunicação Científica. \\ Coordenadora do Laboratório de Investigação em Ciência, \\ Inovação, Tecnologia e Educação.
}

http://dx.doi.org/10.1590/1981-5344/3520

A proposta deste trabalho é realizar uma análise de conjuntura sobre a ciência brasileira, a partir de um olhar sobre a geopolítica do conhecimento, no qual a informação se consolida como uma importante ferramenta de disputa de poder. Neste sentido, a proposta deste ensaio é desvendar os atores e os discursos mercadológicos e ideológicos tanto nas políticas científicas que afetam os comportamentos entre áreas quanto nas disputas de reconhecimento que atravessam os espaços tradicionais de circulação científica. Partimos da noção da existência de um ecossistema dinâmico e complexo no qual os diferentes atores de escala global e nacional estão interligados a partir de disputas e interesses próprios. Resta-nos entender portanto, quem seriam estes atores $e$ quais são os discursos atrelados a esses sujeitos em suas dinâmicas sociais e políticas de circulação do conhecimento e da informação.

Palavras-chave: ecossistema científico, geopolítica do conhecimento, periferia científica, políticas científicas, dinâmicas sociais.

\section{Scientific policies in the knowledge age: a conjuncture analysis of the global scientific ecosystem}

The purpose of this paper is to do a conjuncture analysis on Brazilian science, based on a look at the geopolitics of 
knowledge, in which information is consolidated as an important tool of power dispute. In this sense, the proposal of this analysis of conjuncture is to unveil the actors and the market and ideological discourses both in the scientific policies that affect the behaviors between areas as in the disputes of recognition that cross the traditional spaces of scientific circulation. We start from the notion of the existence of a dynamic and complex ecosystem in which the different actors of global and national scale are interconnected from their own disputes and interests. It remains to be understood, therefore, who these actors would be and what are the discourses linked to these subjects in their social and political dynamics of circulation of knowledge and information.

Key words: scientific ecosystem, geopolitics of knowledge, scientific periphery, scientific policies, social dynamics.

Recebido em 01.05.2018 Aceito em 20.11.2018

\section{Introdução}

Ciência, Tecnologia e Inovação são elementos centrais para o desenvolvimento social e econômico dos países e considerados estratégicos para a geopolítica global, intrinsecamente relacionados com a afirmação social de soberania e democracia dos países. De extrema importância para a sociedade, a comunidade técnico-científica emerge como um importante e estratégico agrupamento social, buscando sua legitimação não apenas entre os seus pares, mas também junto aos outros atores que fazem parte do ecossistema científico das sociedades, através de ferramentas de comunicação científica, tanto na disseminação quanto na divulgação da ciência (BUENO, 1984).

A analogia do ecossistema é utilizada aqui para enfatizar as interdependências mútuas e os efeitos da sinergia na criação de conhecimento em uma rede de interações complexas, uma vez que a produção e consumo de novos conhecimentos é nutrida pela existência prévia de conjuntos de conhecimento dinâmicos relevantes (MAZLOUMIAN, et al, 2013). A escolha deste conceito analógico vai ao encontro de pesquisas que buscam entender mercados financeiros dinâmicos em sua evolução de economias nacionais (MAY; HALDANE, 2011). As redes e as trocas interacionais neste complexo sistema são apontadas por alguns autores que utilizam a metáfora para entender as mudanças nos incentivos e requisitos científicos, similares ao como os ecossistemas biológicos se adaptam às pressões seletivas (SMALDINO; MCELREATH, 2016). É neste sentido que se torna crucial entender estes atores a partir de uma rede de interdependência, observando as 
transformações que ocorrem a partir dos fatores externos ao ambiente científico. Pesquisadores, instituições de pesquisa, mercados editoriais, políticas científicas, redes sociais acadêmicas e não acadêmicas, agências de fomento, políticas públicas, esferas instituições de decisão política na Ciência, Tecnologia e Inovação, leitores, cidadãos comuns e etc. são alguns dos inúmeros atores que compreendem esse complexo sistema dinâmico em constante transformação (PONTE et al, 2017) e disputas. Esta transformação da cadeia de produção e consumo de conhecimento científico implica novos papéis e novos elos entre os atores do ecossistema científico, que muda à medida que as partes interessadas se posicionam em um crescente mercado midiatizado (OLIVEIRA, 2018).

A rápida difusão das novas tecnologias de comunicação cria uma necessidade urgente de repensarmos as forças complexas e multifacetadas que estão remodelando a comunidade científica a partir do entendimento de seu sistema complexo. Para tanto, é necessário entender a conjuntura através de um olhar sobre o conjunto de atores diversos e suas práticas de disputas de poder em um cenário para além de uma realidade local ou nacional, mas a partir de uma compreensão mais ampla sobre a circulação científica em seu panorama global.

Entendemos por sistema, em sua definição mais básica, como um conjunto de elementos inter-relacionados, devedora da Teoria Geral dos Sistemas, na qual se entende que os sistemas vivos, sejam indivíduos ou organizações, devam ser analisados como sistema abertos e dinâmicos. É neste sentido que a Teoria de Sistema nos permite refletir sobre os fenômenos em uma abordagem global, entendendo que variáveis externas e internas, além de macroambientes, influenciam em todo o processo existente na organização (BOULDING, 1956). Portanto, a partir da Teoria Geral dos Sistemas, é possível pensar no sistema científico como um ecossistema, como espaço dinâmico e complexo, com organismos vivos interdependentes e agem de maneira interconectada, se afetam mutuamente e são afetados pelo atores humanos e não-humanos do ambiente do qual se adaptam e nos quais as fronteiras de diferentes esferas da vida são permeáveis (RUOTSALAINEN;HEINONEN, 2015).

Numa esfera global, levando em consideração que o conhecimento através da ciência, tecnologia e inovação são áreas estratégicas, no qual as disputas de capitais econômicos em uma geopolítica do conhecimento são baseadas na privatização do saber, é necessário, portanto, olhar para este ecossistema científico vivo e complexo que emerge na ciência contemporânea. Pautadas em práticas que vem sido consolidadas por países hegemônicos, esse ecossistema científico que se estabelece a partir de um conglomerado econômico é gestado por mercado científico composto por empresas editoriais que ditam as normas de qualidade do conhecimento científico, formando um oligopólio no qual seu lucro é baseado na comercialização do conhecimento (LARIVIĖRI; HAUSTEIN; MONGEON, 2015) e elevam ao status de hegemonia um conjunto de países que vem dominando o mercado científico há mais de 350 anos.

Tal panorama aponta para dois movimentos correlatos: o primeiro diz respeito à própria dinâmica da disseminação no mercado científico 
global, que tem como promessa a legitimação e uma visibilidade maior às produções indexadas nestas bases que compõem o oligopólio científico. Contudo, se a produção não está totalmente presente nestes espaços legitimados da ciência hegemônica, os pesquisadores brasileiros buscarão outras formas de se promover e dar visibilidade aos seus trabalhos para a construção de reputação, sobretudo em redes sociais acadêmicas e não acadêmicas, baseados nos princípios de universalidade da ciência (MERTON, 1973), ao utilizar plataformas comerciais e iniciativas colaborativas para a divulgação de seu próprio trabalho. De acordo com pesquisas realizadas anteriormente (OLIVEIRA, 2018), a busca por estratégias de divulgação da produção científica nas redes sociais é decorrente de um imperativo da visibilidade, na qual há uma intersecção entre as esferas públicas e privadas, na medida em que para estar presente nos circuitos cotidianos é preciso também estar visível e interconectado nos espaços dos fluxos digitais. Como consequência do imperativo da visibilidade na lógica da conexão em redes sociais digitais, os pesquisadores buscam construir uma reputação junto aos seus pares, ao passo que concorrem ao espaço de legitimação e de influência na comunidade acadêmica por meio de uma maior visibilidade de sua produção, compartilhada nos espaços sociais digitais, sobretudo em plataformas acadêmicas. ResearchGate, Academia.edu, entre outros gerenciadores como Mendeley ou espaços de publicação de pareceres abertos, como Publons, são exemplos de como estas redes sociais digitais têm crescido para dar visibilidade à produção técnico-científica, muitas vezes invisíveis no circuito global da ciência. Estas plataformas utilizadas para a divulgação do trabalho científico vêm reconfigurando o ecossistema científico ao prover formas alternativas de se avaliar o "impacto social da ciência". Movimentos como altmetria e ofertas de mensuração da circulação científica como Altmetrics vão surgindo neste cenário para abarcar esse recente interesse acadêmico em relação à visibilidade de suas produções científicas. Levando em consideração que a Ciência é uma área estratégica, e que a internet e os sites e plataformas de redes sociais não são ocupados apenas por pesquisadores, mas compõe um ecossistema próprio na qual se estabelecem diferentes dinâmicas sociais, é necessário entender o que tem sido falado sobre ciência nas redes sociais. Não se trata apenas de olhar para os sujeitos de investigação, ou seja, pesquisadores, estudantes, cientistas e instituições de pesquisa, mas entender como a ciência tem sido repercutida nas redes sociais, buscando identificar as disputas de poder sobre os atores e sujeitos interacionais nas redes sociais.

Para entender este cenário em sua maior abrangência é necessário olhar tanto para a geopolítica, as políticas estruturais dos sistemas institucionais e como elas afetam os comportamentos dos pesquisadores em diferentes áreas do conhecimento e as políticas derivantes dos processos políticos do qual o país atravessa e que tem afetado os investimentos em Ciência, Tecnologia e Inovação. Assim, nos interessa olhar tanto para as redes políticas quanto suas arenas (FREY, 2009), buscando entender o momento atual que enfrenta a ciência brasileira. 
Portanto, este trabalho busca evidenciar as disputas em torno da circulação científica brasileira, tanto nos circuitos tradicionais quanto nas redes sociais, atravessadas por um mercado científico altamente lucrativo pautado na subserviência de países semiperiféricos que servem como mordomos para a manutenção de poder dos países centrais; pelos mecanismos de construção de reputação a partir de políticas públicas que afetam o comportamento dos pesquisadores em diferentes áreas do conhecimento; e por novos mercados que se consolidam em torno do trabalho acadêmico. Esta análise é marcada pela importância de se entender os contextos sociais e não apenas para as métricas que vem sido regidas as discussões em torno da ciência nos espaços acadêmicos, a fim de entender como as políticas estão integradas e o que isso pode nos responder sobre a conjuntura nacional dos países semiperiféricos. Este é um cenário que diz respeito ao Brasil, mas que se refere a uma lógica de interesses e disputas globais em torno do conhecimento como mercadoria e conhecimento como instrumento de disputa de poder.

\section{Geopolítica e políticas do conhecimento}

O século XXI é frequentemente referido como o advento de uma sociedade do conhecimento global (DUARTE, 2003; BURSCH, 2005), impulsionado pelos avanços das tecnologias de comunicação e informação, que incutem um padrão sócio-técnico-econômico emergente e aceleram o processo de globalização (LASTRES; ALBAGLI, 1999). Nesta sociedade do conhecimento, a ciência tem ocupado o papel central na produção de conhecimento moderno, considerado um fator de distinção da capacidade de produção dos países e determinante para o desenvolvimento econômico das nações. Portanto, este conhecimento científico, na junção com um projeto hegemônico neoliberal, tem sido utilizado como aparelho ideológico e instrumento de dominação e poder na sociedade do conhecimento.

No entanto, esta consolidação não surge no século XXI, ou antes, na considerada era pós-industrial, mas tem início há mais de três séculos com o surgimento das editoras científicas. Fundadas com a intenção de promover o conhecimento científico, estas editoras estabeleceram os princípios da prioridade científica e a revisão pelos pares, prometendo facilitar a comunicação da ciência. Desde o século XIX, tem se tornado um eficiente instrumento de comunicação científica (MEADOWS, 1999), atuando sobre a difusão e indexação dos artigos publicados em suas bases. Após a década de 1990 e a popularização da internet, reformulações econômicas e nos modelos de negócios dessas editoras começaram a emergir no ecossistema científico, em um mercado de publicação científica complexo e dinâmico, no qual editoras se fundem com competidores compondo um enorme oligopólio científico (LARIVIÈRI; HAUSTEIN; MONGEON, 2015). Tal oligopólio é formado por seis grandes editoras: ACS, Reed-Elsevier, Springer, Wiley-Blackwell, Taylor \& Francis, e Sage, possuindo juntas um lucro de mais de 9 bilhões de dólares anuais. 
Desde então, a promessa de facilitação da comunicação científica, que até a popularização da internet era um dos entraves para a difusão do conhecimento, sendo necessário recorrer à troca de cartas, seminários e dependências das associações científicas, foi substituída pela promessa de qualidade, legitimação e visibilidade científica por este oligopólio editorial.

A consolidação desta indústria de publicação científica tem sido tema de muito debate dentro e fora da comunidade científica, especialmente em relação às altas margens de lucro das principais editoras, seus critérios pouco transparentes de avaliação de títulos e a publicação de produções de pesquisadores, em sua maioria, europeus e norte-americanos, silenciando e tornando invisível o conhecimento desenvolvido em outros países, sobretudo em áreas consideradas menos estratégicas para a agenda global (RAFOLS; MOLA-GALLARD, 2016).

Porém, este ecossistema não é composto apenas pela divisão abissal entre centros e periferias, pegando o termo de empréstimo de Boaventura de Souza Santos (2007) sobre a emergência de epistemologias do Sul. Além dos centros e periferias, este ecossistema científico também é composto por um conjunto de países considerados semiperiféricos tanto por indicadores econômicos quanto científicos (CONFRARIA; GODINHO; WANG, 2017), que servem de mordomos aos países hegemônicos ao "imitar seu mestre e desprezar membros de sua própria classe" (BENNET, 2014, p. 157), a partir de um conjunto de práticas que excedem a publicação como resultado final do processo de produção de conhecimento.

Se os produtos resultantes das produções do trabalho acadêmico também servem aos interesses comerciais das editoras dos países hegemônicos, é necessário olhar, portanto, para as estratégias adotadas para a manutenção de poder desses países e suas instituições, como parte desse complexo ecossistema científico. Interessa-nos discutir quais seriam os conjuntos de práticas adotadas pelos países hegemônicos para a manutenção de seu poder, a partir de três parâmetros que permeiam o processo de produção de conhecimento no ecossistema científico: políticas de avaliação, políticas científicas de subserviência e políticas neoliberais para o ensino superior.

\section{1) Indicadores de avaliação na cultura da citação}

Para entender esse cenário de disputas sobre a produção da Ciência, torna-se cada vez mais fundamental compreender e monitorar os processos de produção, difusão e circulação dos conhecimentos científicos. Neste cenário, são cada vez mais recorrentes o uso e a construção de indicadores de Ciência, Tecnologia e Inovação (CT\&I) que são de fundamental importância para o melhor entendimento dos processos de circulação do conhecimento científico que ocorrem em cada país. É a partir desses indicadores que se fundamentam e se formulam as políticas científicas nacionais, tendo o objetivo de posicionar a Ciência estrategicamente, visando elevar qualitativamente e quantitativamente o grau de impacto e de competitividade de uma região ou de um determinado país. 
Nas últimas décadas, facilitados pelo desenvolvimento de softwares para coleta e tratamento de dados, avanço dos conhecimentos sobre Big Data, e disseminação do uso de programas estatísticos, uma "maré de métricas" (WOUTERS et al, 2015) vem dominando as discussões sobre estudos relacionados ao uso e análise de indicadores de CT\&I. Mesmo diante de tantas críticas sobre esse processo de metrificação da Ciência, como a Declaração de São Francisco (2012) e o Manifesto de Leiden (HICKS, 2015), tais indicadores têm sido indispensáveis e vem pautando políticas científicas de diversos países e instituições para a avaliação da qualidade da produção científica e para o desenvolvimento de comparações entre países, indústrias e organizações públicas e privadas. Conforme apontam Cassiolato et al (2008), a maioria dos estudos não trata das questões relacionadas aos problemas da "medição" e simplesmente adotam um conjunto de indicadores que aparentemente são amplamente aceitos pela literatura mais tradicional e, com base nestes desenvolvem análise comparativas de países, regiões, setores e empresas, ignorando muitas vezes particularidades da circulação científica de cada país.

Um dos indicadores mais comumente utilizados é o Fator de Impacto, criado por Eugene Garfield, fundador do Institute for Scientific Information (ISI), é considerado um dos pais do que conhecemos hoje como cientometria, juntamente com outros grandes pensadores de sua geração como Robert Merton (1973) com a Sociologia da Ciência e as teorias quantitativas de citações científicas, defendidas por Derek J de Solla Price (1976). O método de indexação de Garfield se estabelece a partir do pressuposto de que quanto mais se cita um trabalho, maior é sua importância ou seu impacto em seu âmbito científico, o que deu início à uma "cultura da citação". (WOUTERS et al, 2015).

A ISI, fundada por Garfiled, em 2008 tornou-se parte da Thomson Reuters, multinacional de meios de comunicação e informação fundada em Toronto, fruto da aquisição da britânica Reuters pela canadense Thomson Corporation. Desde 2016, foi incorporada pela Clarivate Analytics, formada por um grupo de investidores de capital privado liderado pela canadense Onex Corporation e Baring Private Equity, uma das grandes empresas de capital estrangeiro que teve sua origem na britânica Barings Bank e comprada em 2005 pela MassMutual, companhia de seguros de vida norte-americana. A Baring Private Equity International, que incluiu equipes de investimento na Ásia, Índia, Rússia e América Latina, foi adquirida pelas suas respectivas equipes de gestão, que hoje incluem Baring Vostok Capital Partners na Rússia, GP Investments no Brasil, bem como Baring Private Equity Asia e Baring Private Equity Partners Índia. Atualmente, a Clarivate Analytics se concentra na pesquisa científica e acadêmica, na análise de patentes e nos padrões regulatórios, proteção de marca, inteligência farmacêutica e de biotecnologia, proteção de marca de domínio e gerenciamento de IP, mercados de capital financeiro em ascensão.

Tais grandes multinacionais vêm pautando a forma de se avaliar a ciência, utilizando os dados obtidos a partir de suas bases para tomada de 
decisão sobre os investimentos científicos em diversos países, como relatou o próprio Garfield (1998) sobre a decisão de investimento científico na Rússia, pela Fundação Soros, prejudicando cientistas e áreas pequenas, de interesses locais, que publicavam em seu idioma nativo ou até mesmo em inglês em revistas russas que não alcançam impacto significativo em comparação às revistas consideradas internacionais, ou seja, de origem norte-americana ou de alguns países europeus.

Outros indicadores têm sido apresentados como parte desta cultura da citação imposta pelas empresas que dominam o mercado científico. Até 2004, a base Journal Citation Reports (JCR), que publica o Fator de Impacto não tinha fortes concorrentes, quando a Elsevier criou a base Scopus (Nassi-Calò, 2017), propondo o índice SCImago Journal \& Country Rank (SJR), em 2008, disponibilizado em acesso aberto, diferentemente do modelo de negócios adotado pela Clarivates, que limita o acesso à base apenas para seus assinantes. É conhecida como Reed Elsevier, parte do RELX Group, uma das maiores fornecedoras de informação de âmbito global estando cotada na bolsa de valores, como um dos constituintes do índice FTSE 100, Financial Times Global 500 e índice Euronext 100, importantes indicadores de ações globais. O Grupo RELX opera em quatro segmentos de mercado: 1) Científico, Técnico e Médico, sob a marca Elsevier, na qual atua Science Direct, base de dados on-line de pesquisa primária, Scopus, banco de dados bibliográfico a partir do qual é gerado o SJR, e Mendeley, gerenciador de referência, sendo uma das plataformas utilizadas para métricas alternativas, a ser discutido posteriormente; 2) Risk \& Business Analytics, sob as marcas LexisNexis Risk Solutions e Reed Business Information, que fornece ferramentas de tomada de decisão que ajudam os bancos a detectar lavagem de dinheiro e fraudes pelas companhias de seguros (COOKSON, 2016); 3) Negócios legais, sob a marca LexisNexis, empresa que possui o maior banco de dados eletrônico do mundo para informações legais e de registros públicos e; 4) o nicho de mercado baseado em Exposições, sob a marca Reed Exhibitions, maior empresa de espetáculos do mundo (Corty, 2010).

Em 2012, a partir de um texto publicado em blog pelo britânico Timothy Gowers ${ }^{1}$, a Elsevier enfrentou um boicote apelidado de Primavera Acadêmica $^{2}$ contra os altos custos do conhecimento ${ }^{3}$, cuja adesão alcançou quase 17 mil signatários. Além das altas cobranças de acesso ao conteúdo da base, dentre as principais razões levantadas por Gowers que justificam o boicote tratava-se do apoio da empresa às políticas de restrição como o Research Works Act (RWA), projeto de lei que tramitou no congresso americano e revertia o National Institutes of Health (NIH) Public Access Policy que prezava pelo acesso aberto às pesquisas financiadas pelo governo federal. Denunciado por Mike Taylor (2013), o RWA é co-patrocinado por Darrell Issa (Republicano, Califórnia) e Carolyn B. Maloney (Democrata, Nova York). No ciclo eleitoral de 2012, Elsevier e

$1 \mathrm{http}: / / g o w e r s . w o r d p r e s s . c o m / 2012 / 01 / 21 /$ elsevier-my-part-in-its-downfall/

2 http://www.faz.net/aktuell/feuilleton/forschung-und-lehre/debatte-um-wissenschaftsverlag-akademischerfruehling-11649380.html

3 http://thecostofknowledge.com/ 
seus executivos seniores fizeram 31 doações para representantes do congresso, sendo duas para Issa e 12 para Maloney ${ }^{4}$.

Esta é só uma dentre as muitas táticas de guerrilha para domínio do mercado que a empresa vem exercendo. Além do financiamento e suporte de eventos acadêmicos nas áreas de políticas públicas, bibliometria, editoração científica, entre outras, em diversos países, a empresa ainda busca atuar de muitas formas para se infiltrar nas diferentes maneiras de disseminar o seu conteúdo científico. A exemplo, podemos citar o caso do investimento da empresa na parceria com a Wikipedia. O acordo firmado entre a enciclopédia livre e a Elsevier previa que alguns dos melhores editores da Wikipédia recebessem contas especiais com acesso livre a publicações da editora, a fim de melhorar as matérias do site a partir dos conteúdos de qualidade indexados na Elsevier. No entanto, como o acesso à base é pago, esta iniciativa ajudaria a colocar o conteúdo da empresa em relevância como PageRank, recebendo diversas críticas sobre tal parceria (COSTA, 2015).

Segundo Lilian Nassi-Calò (2017, s/n), "a forma de calcular o SJR e - FI apresentam algumas diferenças, porém ambos basicamente aferem citações por intervalo de tempo e guardam uma relação linear". Outros indicadores baseados em citação têm sido utilizados pela comunidade acadêmica, como o índice $H$, que mede a produtividade e impacto de pesquisadores, periódicos e instituições, Eigenfactor e Scores de Influência, que são medidas de auto-fator que permitem verificar o grau de importância de uma revista dentre o conjunto de outputs pelas citações, ou SNIP (Source Normalized Impact per Paper), que leva em consideração a relevância do periódico e as diferenças entre áreas, entre outros que vêm surgindo em um cenário de métricas alternativas 5 (THELWAL, 2017), que aos poucos vão reconfigurando a forma de se avaliar o trabalho acadêmico.

2) Síndrome de mordomo manifestada nas políticas científicas

Ainda que estejam surgindo outras formas de avaliação e indicadores que possam responder para além dos dados obtidos pela Web of Science ou Scopus, estas duas matrizes continuam sendo utilizadas tanto para a avaliação e mensuração da produção científica de diversos países, sobretudo entre cientistas da informação, como também pautam nossas políticas científicas, em diferentes áreas do conhecimento.

De acordo com o Relatório da Ciência da Unesco (UNESCO's 2010 Science Report), desde o começo do século XXI, países em desenvolvimento tem expandido sua atuação nas produções científicas, devido a um alto investimento de políticas científicas de seus países,

4 Em fevereiro de 2012, a Elsevier emitiu uma declaração no seu site que declarou que retirou o apoio ao RWA, contudo, negando ser uma reação ao boicote e afirmando que tomou a decisão em função de consultas à pesquisadores que não aderiram à Primavera Acadêmica (Howard, 2012). Contudo, não há como mensurar a eficácia do boicote. Segundo estudo realizado por Heyman, Moors, Storms (2016), 38\% já havia abandonado à adesão ao publicar em uma das revistas da Elsevier até 2016.

${ }^{5}$ Vale ressaltar que métricas alternativas não são equivalentes à altmetria, que tem ganhado a atenção da comunidade acadêmica, ao introduzir a repercussão e atenção online da produção científica através de sites de redes sociais e outras plataformas digitais, como Mendeley, Wikipedia, blogs e documentos de políticas públicas. 
medido sobretudo por bibliometrias consolidadas por serviços de indexação. Estudos (WAGNER; WONG, 2011) apontam que, com base nos dados do SCIE, houve um crescimento da produção científica dos países que englobam os BRICS, experimentando um crescimento considerável em seus indicadores. Apesar do crescimento, sua representatividade no SCIE alcança apenas 3\% da produção científica da base. Dentro de SCIE, mais de $50 \%$ das revistas são atribuídas a apenas três países: Estados Unidos (34\%); Inglaterra (19\%) e Holanda ( $8 \%)$ refletindo um viés de língua inglesa, que já havia sido documentado em estudos anteriores (LUUKONEN, 1990). No SCIE/Web of Science, se concentra exclusivamente nas ciências naturais e engenharia, com baixa atuação nas Ciências e Humanidades, além de representar apenas $40 \%$ da produção científica mundial.

O Brasil tem uma pequena presença neste circuito de mercado dominado pelos principais editores científicos. Por exemplo, ao olhar para Cite Score em Scopus (2016), a primeira revista brasileira na lista é o "Ethnobiology and Conservation Journal", ocupando o cargo 2415. Entre os 36,377 títulos indexados em Scopus, apenas $439(1,2 \%)$ são brasileiros e apenas 128 estão presentes na Web of Science, dentre os mais de 10 mil periódicos científicos publicados no Brasil.

Esta presença - ou melhor, baixa presença - não se manifesta apenas nos resultados das pesquisas e produções científicas publicadas nos canais destas bases, mas também pelo pouco reconhecimento de espaços de consagração nessas próprias revistas internacionais. Estes espaços de consagração são os comitês editoriais, que representam um mecanismo fundamental de auto-regulação do funcionamento da atividade acadêmica. Os avaliadores do comitê editorial desempenham um papel importante na avaliação e definição da área (DHANANI et al., 2017), ao validar a pesquisa a ser veiculada nesses espaços de publicação. Composto por um conjunto de pesquisadores que as revistas consideram bem-conceituados e relevantes para as áreas, estes pesquisadores geralmente são convidados a compor o comitê editorial, representando um status de legitimação e de suas próprias trajetórias e autoridade em seus respectivos campos (BRINN; JONES, 2007). O pagamento de seu trabalho geralmente é feito através de status e reconhecimento, sobretudo em revistas bem qualificadas em suas áreas ${ }^{6}$. Todavia, os lucros do oligopólio acadêmico são gigantescos, como falado anteriormente, que utilizam o trabalho acadêmico, gratuitamente, em modelos de negócios altamente lucrativos, restringindo o acesso ao conhecimento científico, sendo este tratado como produto final passível de monetização.

A partir deste lucrativo mercado se consolidam conjuntos de centros hegemônicos, periferias e semiperiferias científicas e que ecoam na

\footnotetext{
${ }^{6}$ Existem diferentes modelos de avaliação pelo comitê editorial, sendo o mais comum o realizado sem compensação financeira, como parte do trabalho acadêmico de avaliação desinteressada (Merton, 1973).
} 
materialização das próprias políticas científicas dos países ${ }^{7}$. No Brasil, as revistas são avaliadas por um comitê ad hoc designado pela área de conhecimento, que determinam os critérios para medir a qualidade desses periódicos e classificados em oito estratos Qualis. Esta classificação é agrupada em nove campos disciplinares: Ciências Agrícolas, Biológicas, Ciências da Saúde, Engenharias, Ciências Exatas, Letras, Linguística e Artes, Ciências Humanas, Ciências Sociais e Multidisciplinares. Como cada campo possui suas próprias prioridades, algumas áreas usam índices bibliométricos, principalmente Fator de Impacto, enquanto outros utilizam avaliações mais subjetivas e qualitativas para avaliar suas revistas científicas, conforme ilustra o quadro abaixo ${ }^{8}$.

Figura 1: Critérios de estratificação Qualis

\footnotetext{
${ }^{7}$ Como pudemos observar no caso do Research World Act, mencionado anteriormente, essa relação de poder e de influência sobre o mercado científico e as políticas científicas não ocorre apenas nos países periféricos ou semiperiféricos, mas também em países centrais, como no caso da Inglaterra.

${ }^{8}$ Atualmente, o sistema de classificação Qualis está sob revisão, tramitando com propostas de Qualis Único no Plano Nacional de Pós-graduação (PNPG) da Capes, enviadas por entidades que integram a comunidade acadêmica, científica e tecnológica do país. Cf. http://www.capes.gov.br/sobre-a-capes/plano-nacional-depos-graduacao
} 


\begin{tabular}{|c|c|c|c|c|c|c|c|c|}
\hline & A1 & A2 & & $\mathrm{D} 2$ & B3 & 104 & D5 & \\
\hline ag & $\begin{array}{l}\text { ISI Serial with } \\
J C R \geq 2.0\end{array}$ & $\begin{array}{l}\text { ISI Serial with } \\
\text { JCR } \geq 1 \&<<2 \\
\text { Braz. JCR }>0.75\end{array}$ & $\begin{array}{l}\text { ISI Serial with } \\
\text { JCR } \geq 0.001 \\
\&<1.0\end{array}$ & $\begin{array}{l}\text { Presence in } \\
4 \text { indexers (1) } \\
\text { databases } \\
\text { ISI with no JCR }\end{array}$ & $\begin{array}{l}\text { Presence in } \\
3 \text { indexers (1) } \\
\text { databases }\end{array}$ & $\begin{array}{l}\text { Presence in } \\
2 \text { indexers (1) } \\
\text { databases }\end{array}$ & $\begin{array}{l}\text { Presence in } \\
1 \text { indexer (1) } \\
\text { database }\end{array}$ & $\begin{array}{l}\text { Do not meet } \\
\text { the criteria or } \\
\text { no articles in } \\
\text { the field }\end{array}$ \\
\hline al & $\begin{array}{l}\text { All from B5 plus: } \\
8 \text { years uninter- } \\
\text { rupted publica- } \\
\text { tion, } 80 \% \text { author } \\
\text { institutional di- } \\
\text { versity, editorial } \\
\text { board with intnl. } \\
\text { PhDs, indexed }\end{array}$ & $\begin{array}{l}\text { All from B5 plus: } \\
7 \text { years uninter- } \\
\text { rupted publica- } \\
\text { tion, } 80 \% \text { author } \\
\text { institutional di- } \\
\text { versity, editorial } \\
\text { board with intnl. } \\
\text { PhDs, indexed } \\
\text { serial }\end{array}$ & $\begin{array}{l}\text { All from B5 plus: } \\
6 \text { years uninter- } \\
\text { rupted publica- } \\
\text { tion, } 70 \% \text { author } \\
\text { institutional d- } \\
\text { versity, editorial } \\
\text { board with intnl. } \\
\text { PhDs, indexed } \\
\text { serial } \\
\end{array}$ & $\begin{array}{l}\text { All from B5 plus: } \\
4 \text { years uninter- } \\
\text { rupted publica- } \\
\text { tion, } 60 \% \text { author } \\
\text { institutional di- } \\
\text { versity, editorial } \\
\text { board with intrl. } \\
\text { PhDs }\end{array}$ & $\begin{array}{l}\text { All from B5 } \\
\text { plus: } 3 \text { years un- } \\
\text { internupted pub- } \\
\text { lication, } 50 \% \\
\text { author institu- } \\
\text { tional diversity, } \\
\text { editorial board }\end{array}$ & $\begin{array}{l}\text { All from B5 } \\
\text { plus: } 2 \text { years un- } \\
\text { interrupted pub- } \\
\text { lication, } 40 \% \\
\text { author institu- } \\
\text { tional diversity }\end{array}$ & $\begin{array}{l}\text { Published } 2 \\
\text { issues in previ- } \\
\text { ous } 2 \text { years, } 30 \% \\
\text { institutional di- } \\
\text { versity, editorial } \\
\text { board, ISSN, } \\
\text { peer review, } 14 \\
\text { art/year }\end{array}$ & $\begin{array}{l}\text { Serials that do } \\
\text { not meet the } \\
\text { criteria to be } \\
\text { B5 }\end{array}$ \\
\hline bio & JCR $\geq 4.3$ & $\begin{array}{l}J C R \geq 3.1 \\
\&<4.3\end{array}$ & $\begin{array}{l}\text { JCR } \geq 2.0 \\
\&<3.1\end{array}$ & $\begin{array}{l}J C R \geq 1.6 \\
\&<2.0\end{array}$ & $\begin{array}{l}J C R \geq 1.1 \\
\&<1.6\end{array}$ & $\begin{array}{l}\mathrm{JCR} \geq 0.5 \\
\&<0.1\end{array}$ & JCR $<0.5$ & $\begin{array}{l}\text { Serials consid- } \\
\text { cred not rel- } \\
\text { evant to the } \\
\text { field }\end{array}$ \\
\hline eng & $\begin{array}{l}\text { JCR }>1.43 \\
\text { in Engineer- } \\
\text { ing or JCR }> \\
4.0 \text { in other }\end{array}$ & $\begin{array}{l}J C R>0.75 \\
\text { in Engineer- } \\
\text { ing or JCR > } \\
1.79 \text { in other } \\
\text { field }\end{array}$ & $\begin{array}{l}\text { JCR }<0.75 \text { in } \\
\text { Engineering or } \\
\text { JCR }>0.1 \text { in } \\
\text { other field }\end{array}$ & $\begin{array}{l}\text { JCR < } 0.1 \text { Indexed } \\
\text { on ISI, SciELO, } \\
\text { SCOPUS \& repre- } \\
\text { sentative non in- } \\
\text { dexed }\end{array}$ & $\begin{array}{l}\text { Indexed on ISI, } \\
\text { SciFLO, } \\
\text { SCOPUS \& not } \\
\text { indexed sernals } \\
\text { from representu- } \\
\text { tive societies in }\end{array}$ & $\begin{array}{l}\text { Scientific serials } \\
\text { with peer review } \\
\text { and editorial } \\
\text { board }\end{array}$ & $\begin{array}{l}\text { Local scientific } \\
\text { serials with no } \\
\text { editorial board } \\
\text { or peer review }\end{array}$ & $\begin{array}{l}\text { Commercial } \\
\text { serials }\end{array}$ \\
\hline ext & $\mathrm{J}^{*}>1.44$ & $\begin{array}{l}J^{*}>1.18 \\
\& \leq 1.44\end{array}$ & $\begin{array}{l}J^{*}>0.9 \& \\
\leq 1.18\end{array}$ & $\begin{array}{l}J^{*}>0.76 \\
\& \leq 0.9\end{array}$ & $\begin{array}{l}J^{*}>0.63 \\
\& \leq 0.76\end{array}$ & $\begin{array}{l}J^{*}>0.18 \\
\& \leq 0.63\end{array}$ & $\begin{array}{l}\mathrm{J}^{*} \leq 0.18 \text { or } \\
\text { Indexed Seri- } \\
\text { als with no IF } \\
\text { Ed. Board, } \\
\text { Peer Review }\end{array}$ & $\begin{array}{l}\text { Serials that } \\
\text { do not meet } \\
\text { the criteria }\end{array}$ \\
\hline hth & $J C R \geq 4.0$ & $\begin{array}{l}J C R \geq 2.8 \\
\&<4.0\end{array}$ & $\begin{array}{l}J C R \geq 1.6 \\
\&<2.8\end{array}$ & $\begin{array}{l}\mathrm{JCR} \geq 0.8 \\
\&<1.6\end{array}$ & $\begin{array}{l}J C R \geq 0.2 \\
\&<0.8\end{array}$ & $\begin{array}{l}\text { JCR }<0.2 \text {, } \\
\text { SciELOO, ISI, Sci- } \\
\text { mago, Medline, } \\
\text { Scopus with no IF }\end{array}$ & $\begin{array}{l}\text { Lilacs, Sportdi- } \\
\text { cus, Latindex } \\
\text { and other data- } \\
\text { bases }\end{array}$ & $\begin{array}{l}\text { Serials consid- } \\
\text { ered not rel- } \\
\text { evant to the } \\
\text { field }\end{array}$ \\
\hline um & $\begin{array}{l}\text { Presence in ISI } \\
\text { and Psycinfo, } \\
\text { international } \\
\text { scientific asso- } \\
\text { ciation serial, } \\
\text { reference to the } \\
\text { field }\end{array}$ & $\begin{array}{l}\text { Presence in ISI } \\
\text { or in PsycInfo, } \\
\text { Scopus and } \\
\text { Scielo, and at } \\
\text { least four } \\
\text { other indexers }\end{array}$ & $\begin{array}{l}\text { Presence in ISI } \\
\text { or PsycInfo, or } \\
\text { Scopus or } \\
\text { Scielo, or at } \\
\text { least four other } \\
\text { indexers }\end{array}$ & $\begin{array}{l}\text { Presence in at } \\
\text { least two index- } \\
\text { ers: IBDs, Clase, } \\
\text { Latindex, Lilacs, } \\
\text { Psicodoc, } \\
\text { Pascal, Redalyc }\end{array}$ & $\begin{array}{l}\text { Presence in one } \\
\text { indexer: IBDs, } \\
\text { Clase, Latindex, } \\
\text { Lilacs, Psico- } \\
\text { doc, Pascal, Re- } \\
\text { dalyc }\end{array}$ & $\begin{array}{l}\text { Published by } \\
\text { Scientific Asso- } \\
\text { ciation or Uni- } \\
\text { versity, peer- } \\
\text { reviewed, with } \\
\text { CAPES or } \\
\text { CNPq support }\end{array}$ & $\begin{array}{l}\text { ISSN, peer Re- } \\
\text { viewed, submis- } \\
\text { sion rules, } \\
\text { inform editor, } \\
\text { editorial com- } \\
\text { mittee, review- } \\
\text { ers, } 2 \text { issues year }\end{array}$ & $\begin{array}{l}\text { Serials that do } \\
\text { not meet the } \\
\text { criteria }\end{array}$ \\
\hline nult & $J C R \geq 4.34$ & $\begin{array}{l}J C R \geq 3.25 \\
\&<4.34\end{array}$ & $\begin{array}{l}\text { JCR } \geq 2.17 \\
\&<3.25\end{array}$ & $\begin{array}{l}J C R \geq 1.4 \\
\&<2.17\end{array}$ & $\begin{array}{l}\text { JCR } \geq 0.8 \\
\&<1.4\end{array}$ & $\begin{array}{l}\text { JCR } \geq 0.1 \\
\&<0.8, \text { or } \\
\text { Serials in }\end{array}$ & $\begin{array}{l}\text { JCR }<0.1 \text { or In- } \\
\text { dexed Servals with } \\
\text { no IF } \\
\text { Editorial Board, } \\
\text { Peer Review }\end{array}$ & $\begin{array}{l}\text { Serials not rel- } \\
\text { evant to the } \\
\text { ficld }\end{array}$ \\
\hline ssc & $\begin{array}{l}\mathrm{SH}>20 \\
\text { or } \\
\mathrm{JCR}>1 \\
(3)\end{array}$ & $\begin{array}{l}\mathrm{SH}>4 \& \leq 20 \\
\text { or } \\
\mathrm{JCR} \leq 1 \&> \\
0.2\end{array}$ & $\begin{array}{l}\text { All from B2 plus: } \\
\text { SH } \leq 4 \text { or JCR } \leq \\
0.2(3) \text {, SciELO } \\
\text { or RedAL,yC, or } \\
\text { periodical from } \\
\text { intemational pub- } \\
\text { bsher (4) }\end{array}$ & $\begin{array}{l}\text { All from } B 3 \text { plus: } \\
\text { indexed(5) more } \\
\text { than three years, } \\
\text { inform report the } \\
\text { evaluation pro- } \\
\text { cess }\end{array}$ & $\begin{array}{l}\text { All from B4 plas: } \\
\text { Have mission, } \\
\text { editorial board, } \\
\text { minimum of two } \\
\text { issues per year, } \\
\text { full article details }\end{array}$ & $\begin{array}{l}\text { All from B5 } \\
\text { plus: is Peer Re- } \\
\text { viewed, have } \\
\text { submission } \\
\text { rules }\end{array}$ & $\begin{array}{l}\text { Have ISSN and } \\
\text { defined period- } \\
\text { icity }\end{array}$ & $\begin{array}{l}\text { Serials that do not } \\
\text { meet the criteria } \\
\text { to be B5 or have } \\
\text { not published ar- } \\
\text { ticles in previous } 3 \\
\text { years }\end{array}$ \\
\hline & $\begin{array}{l}\text { IF = Impact Fad } \\
\text { (1) Indexers in t) } \\
\text { (3) Which is mo } \\
\text { (5) in Scopus, E }\end{array}$ & $\begin{array}{l}\text { ICR }= \\
\text { rricultural Fi } \\
\text { rorable to th }\end{array}$ & $\begin{array}{lll}\mathrm{CAB}, \mathrm{BIOS} & \text { (4) } \mathrm{S}\end{array}$ & $\begin{array}{l}\text { SRIS, AGRI } \\
\text { Isevier, Eme: }\end{array}$ & $\begin{array}{r}\mathrm{SH} \\
\mathrm{A}, \mathrm{Sci}\end{array}$ & 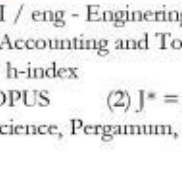 & 11 & $\begin{array}{l}\text { ence } \\
\text { (2013) }\end{array}$ \\
\hline
\end{tabular}

Fonte: Carvalho Neto, Willinsky e Alperin, 2016.

Analisando as políticas científicas brasileiras, o país ocupa uma posição semiperiférica (BENNETT, 2014) em algumas áreas do conhecimento. No entanto, áreas como Doenças Tropicais Negligenciadas, Odontologia, entre outras, são consideradas áreas nas quais o Brasil se encontra em posição de destaque no cenário científico mundial, com avanços de pesquisa que tornam a produção de conhecimento brasileira centros de excelência científica e tecnológica. Seguindo a Teoria do Sistema Mundo (HOPKINS; WALLERSTEIN, 1982) ainda, outras áreas seriam consideradas periféricas, tornando-se invisíveis no circuito hegemônico. Portanto, atentar para esta classificação mundial dos sistemas, requer um olhar mais complexo, buscando aprofundar sobre as assimetrias e particularidades de cada uma das áreas do conhecimento. 
E entendendo o ecossistema científico a partir da noção da Teoria Geral dos Sistemas é possível observar que as dinâmicas de cada área, manifestada a partir das próprias políticas científicas, afetam diretamente a forma de classificação de suas práticas de produção de conhecimento global. Em outras palavras, algumas áreas do conhecimento que utilizam as métricas de índice dos editores de oligopólios são impelidas a competir com a publicação científica que supostamente estão no centro desta pesquisa científica.

Como consequências, vemos uma menor atuação de revistas científicas dessas áreas que adotaram o FI como critério de avaliação sendo gestadas pelo próprio país. Ao comparar duas áreas com perfis diferentes, é possível observar alguns resultados destas políticas com mais clareza. Por exemplo, na área de biodiversidade, da qual possui critérios de avaliação baseados somente em JCR em todos os estratos, é possível verificar que dentre as 190 revistas avaliadas como A1 no Qualis (quadriênio 2013-2016), nenhuma era brasileira, enquanto que em Artes, cujos critérios de avaliação Qualis se baseiam em critérios mais flexíveis como comitê editorial composto por doutores ou diversidade institucional, 10 de $19(52,6 \%)$ são revistas brasileiras. Na área de biodiversidade, 144 revistas $(74,7 \%)$ pertencem ao grupo que formam o oligopólio das editoras acadêmicas (LARIVIÈRI; HAUSTEIN; MONGEON, 2015), sendo mais de 50 títulos da Wiley-Blackwell ${ }^{9}$.

A complexidade da semiperiferia se estabelece também pela distinção entre áreas e as disputas de poder econômico e ideológico que se inter-relacionam nas esferas globais e locais. Se em algumas áreas o comportamento científico é voltado para uma inserção cada vez maior ao cenário de hegemonia global, refletido e sendo refletido por políticas científicas destas áreas que estabelecem métodos de avaliação da ciência a partir dos modelos hegemônicos, em outras áreas, sobretudo humanas, estes modelos são pautados a partir de outros critérios que dizem respeito a uma reputação construída a partir de relações de influência na comunidade científica nacional e que compõem o amplo espectro do trabalho acadêmico.

\section{3) Agenda neoliberal da universidade pública no Brasil}

A relação entre a universidade brasileira e a agenda neoliberal é estreita e encontra suas origens na própria consolidação do sistema educacional-científico do Brasil. A forte influência exercida por organizações financeiras mundiais na política brasileira se reflete sobre os diversos setores, como o ensino e a pesquisa no país, para garantir a preponderância do monopólio de interesses de alguns países sobre os demais, infringindo os próprios interesses nacionais e sua soberania.

Segundo Roberto Leher (1998), a manutenção de poder dos países hegemônicos se dá através de cinco monopólios chaves: tecnológico, no fluxo financeiro mundial, no acesso aos recursos naturais, de comunicação

\footnotetext{
Um estudo inicial demonstrou que apenas 13 brasileiros compõem o comitê editorial das revistas na área de biodiversidade. Estes dados, assim como presença e circulação das publicações nesta área, serão apresentados em trabalhos futuros.
} 
e de armamentos de destruição massiva. Todos esses monopólios são de extrema importância na Pesquisa, Desenvolvimento e Inovação (PD\&I), fortalecendo a relação universidade-indústria-governo, que formam a "hélice tríplice" de inovação e empreendedorismo, sendo considerada a chave para o crescimento econômico e o desenvolvimento social baseados no conhecimento (ETZKOWITZ; ZHOU, 2017). A tese da Hélice Tríplice é que a universidade está deixando de ter um papel unicamente voltado para o ensino superior e pesquisa, e está assumindo um papel primordial equivalente ao da indústria e do governo, como geradora de novas indústrias e empresas. Contudo, como apontam alguns estudos, esta não é uma realidade fiel ao cenário nacional, visto que a transferência do conhecimento em inovação depende de políticas públicas e uma mudança na cultura técnico-científica nacional.

Esta relação entre universidade, governo e indústria, através das parcerias público-privadas, é reconhecida como importante esfera da sociedade desde o século XVIII. No Brasil, este cenário se desenvolveu em outra temporalidade. Segundo Guimarães (1996), a política científica e tecnológica se concentrou exclusivamente na concessão de apoio financeiro às atividades de ciência e tecnologia (C\&T) até a década de 1990, apesar da criação e importantes centros de pesquisa e desenvolvimento durante o regime militar e após a instabilidade da década de 1980 associada à recessão econômica, multiplicação dos atores e arenas na competição por recursos públicos e crescimento do clientelismo político. Segundo Ireni Zago Figueiredo (2009), com a perda das atribuições da UNESCO para o Banco Mundial e, o debate sobre a educação foi se transformando em assunto de negócios, de banqueiros e de estrategistas políticos.

Esse conjunto de instabilidades contribuiu para que o Fundo Monetário Internacional (FMI), o Banco Internacional para a Reconstrução e o Desenvolvimento (BIRD)/Banco Mundial e o Banco Interamericano de Desenvolvimento (BID), propusessem uma série de condicionalidades econômico-financeiras e educacionais, além de político-ideológicas, através de propostas de planos de estabilização econômica, tal como evidenciamos este ano com a proposta de acabar com o ensino superior gratuito apresentada pelo Banco Mundial, em novembro de 2017, em um plano de ajuste fiscal.

Segundo Oliveira e Fonseca (2001), é possível afirmar que a cooperação técnica e financeira de entidades financeiras internacionais, como o Banco Mundial, não constituiu uma interação neutra, mas um mecanismo de difusão de concepções ideológicas internacionais, capazes de orientar a agenda do setor sob o financiamento científico.

Esta é apenas uma das muitas formas de ataques articulados com uma agenda neoliberal e conservadora que a universidade brasileira tem enfrentado depois do golpe de 2016, e que visam o desmonte da educação superior pública e de qualidade. Cientes da importância de investimentos em Ciência, Tecnologia e Inovação esses ataques visam colocar o Brasil de um patamar de subserviência própria dos países semiperiféricos a um potencial comprador de tecnologia internacional e 
uma filial de um sistema de ensino superior comandado por poderosos grupos econômicos internacionais. International Branch Campus tem sido a tendência de investimentos educacionais de grandes empresas do ensino superior e pesquisa que ocupam os principais rankings de avaliação do mundo. Os países que possuem mais investimentos educacionais filiados em outros países são: Estados Unidos (108), Reino Unido (44) e França (31), em sua maioria de investimentos Norte-Sul, em países com menor tributação e com diferentes modelos de negócios e de sustentabilidade como estratégias para uma educação transnacional (VERBIK, 2015; WILKINS; HUISMAN, 2012). Em seguida, Rússia (24) e Austrália (22) despontam como países com mais investimento educacional transnacional. Os maiores hospedeiros são: China (40), Emirados Árabes - Dubai (38), Malásia (16), Singapura (15) e Canadá (12), sendo este último em sua maioria de empresas educacionais dos Estados Unidos. 0 Brasil hospeda algumas filiais: a francesa Skema, localizada em Belo Horizonte e Manchester Business School, em São Paulo com parceria com a Fundação Getúlio Vargas, um dos escritórios de Harvard em São Paulo e do anúncio de uma filial da empresa no Estado do Rio de Janeiro, onde já está instalado o Columbia Global Centre, além de uma forte presença da rede Laureate International Universities, rede global de instituições acadêmicas privadas, criada nos Estados Unidos na década de 1990.

A proposta de ajuste fiscal do Banco Mundial não fora um acontecimento isolado, mas faz parte de um conjunto de táticas que estão sendo direcionadas contra a comunidade científica, a reboque dos cortes orçamentários para Ciência, Tecnologia e Inovação nos últimos anos (ver Fig. 03). O valor aprovado para o Ministério da Ciência, Tecnologia, Inovações e Comunicação (MCTIC) para 2018 é cerca de 19\% menor do que foi o ano de 2017; já o orçamento destinado a custeio e investimento é cerca de $25 \%$ menor do que fora este ano e já se configurou com uma trajetória de queda das verbas federais para pesquisa, que vem se acentuando desde 2015. Esses cortes ameaçam o funcionamento do sistema nacional de CT\&I do Brasil.

Antes mesmo da publicação do plano de ajuste fiscal do Banco Mundial, e a reboque de ataques jurídico-financeiro-midiático, o jornal 0 Globo, em julho de 2017, já preconizava a proposta da instituição financeira, ao enfatizar a necessidade de dar um fim ao ensino público no Brasil $^{10}$. Em seu editorial, o jornal indagava: "por que não aproveitar para acabar com o ensino superior gratuito, também um mecanismo de injustiça social?". Com base em uma pesquisa publicada pela Folha de São Paulo, em julho de $2014^{11}$, afirmava ser injusto, o sistema de ingresso e permanência na universidade, visto que $60 \%$ dos alunos matriculados poderiam pagar suas mensalidades, podendo adotar uma arrecadação de mais de 1,8 bilhão na USP, caso adotassem um modelo misto de pagamento para graduação e pós-graduação combinado com concessão de bolsas para graduação para alunos de faixas salarias mais baixas.

10 https://oglobo.globo.com/opiniao/crise-forca-fim-do-injusto-ensino-superior-gratuito-19768461

11 http://www1.folha.uol.com.br/educacao/2014/06/1463535-mensalidade-na-usp-poderia-ser-paga-por-60dos-alunos.shtml 
Ainda em dezembro de 2017, a Veja ${ }^{12}$, através do jornalista Cláudio Castro, publicou uma matéria que apontava a necessidade de repensar os modelos em prol de impulsionar a excelência - preferencialmente pago. Esses são alguns exemplos de como a mídia massiva tem sido utilizada como um instrumento de ataques articulados contra a universidade pública. Porém não foram os únicos.

Em setembro de 2017, O reitor da Universidade Federal de Santa Catarina (UFSC), Luiz Carlos Cancellier de Olivo, foi preso na Operação "Ouvidos Moucos", pela Polícia Federal, investigado pela delegada Érika Mialik Marena, ex-coordenadora da Operação Lava Jato, em Curitiba. Com apoio da Controladoria Geral da União e Tribunal de Contas da União, o reitor foi acusado de desvio de recursos para cursos de Educação a Distância (EaD) da UFSC. Algemado e interrogado por mais de sete horas, o reitor foi preso por obstrução da justiça e solto um dia depois, tendo sido impedido por ordem judicial de entrar na universidade. No dia 02 de outubro de 2017, Cancellier cometeu suicídio 18 dias após sua prisão. Em dezembro de 2017, a delegada Erika Mialik Marena foi promovida para superintendente da Polícia Federal em Sergipe. Assim como o que ocorre na operação Lava Jato, o caso da UFSC também foi construído em torno da transformação da agenda política em espetáculo seriado, midiatizando pautas de interesse da sociedade como entretenimento mascarado por posicionamentos políticos. Outro caso recente também foi conduzido, desta vez tendo como alvo os reitores da Universidade Federal de Minas Gerais (UFMG). A Operação "Esperança Equilibrista", em alusão à canção "O Bêbado e a Equilibrista", composta durante a ditadura militar, tinha como propósito apurar suspeitas de desvio de recursos destinados à construção do Memorial da Anistia Política na UFMG. Outras operações foram realizadas em operações policiais nos casos de suspeita de desvio de bolsas na Universidade Federal do Paraná, em fevereiro de 2017, Universidade Federal do Rio Grande do Sul e Unisinos, em dezembro de 2016. Acontecimentos como estes estão vindo à tona a partir da tramitação de projetos de lei como o "Escola Sem Partido", que cerceia a liberdade de cátedra e uma das principais plataformas políticas do então candidato eleito à presidência, Jair Bolsonaro (PSL - Partido Social Liberal). À controversa da proposta, no dia 11 de novembro de 2018, o Ministério da Educação autorizou a criação de uma faculdade ligada à Igreja Universal, pela fundação do Partido Republicano Brasileiro (PRB), que integra a base governista do então presidente Michel Temer (MDB) e tem afinidades ideológicas com Jair Bolsonaro.

Juntamente aos movimentos político-partidários e ataques jurídicomidiáticos pela privatização e cerceamento da universidade, estamos acompanhando o desmonte de programas de pós-graduação de universidades privadas, como na Universidade Metodista e Pontifícia Universidade Católica do Rio Grande do Sul, além de demissões em massa de grandes conglomerados educacionais como Estácio de Sá e Anhembi,

12 https://veja.abril.com.br/revista-veja/a-universidade-publica-em-xeque/ 
entre outras universidades como Uniritter, Faculdades Metropolitanas Unidas e Fadergs que compõe o quadro da Laureate.

Esse conjunto de fatores - indicadores de avaliação na cultura da citação como avaliação, a síndrome de mordomo que se manifesta nas políticas científicas e uma agenda neoliberal imposta no ensino superior no Brasil - são algumas das práticas que atuam em prol de uma manutenção de poder dos países hegemônicos, apontando não para uma Ciência Invisível dos países periféricos ou semiperiféricos, mas uma invisibilização da produção científica desses países que não compõem o circuito científico tradicional dominante.

Contudo, como as revoluções científicas acontecem a partir de rupturas de sistemas científicos consolidados a partir do surgimento de novos paradigmas (KUHN, 1963), o ambiente científico hegemônico tem sido "ameaçado" também por um conjunto de práticas de disrupção que surgem no ecossistema científico, advindas sobretudo de países que não compõem o eixo dominante da ciência. Exemplos como Open Access, SciHub, Preprints, disseminação da produção científica em plataformas sociais digitais e circulação e compartilhamento científico na deepweb, são alguns desses exemplos de práticas disruptivas ou alternativas que vêm surgindo no ecossistema científico global. Evidentemente, por se tratar de um sistema complexo e dinâmico, novos modelos de negócios também se consolidam e se estabelecem a partir destas práticas alternativas, surgindo novos negócios na complexa sociedade do conhecimento contemporânea. Por exemplo, podemos ver como algumas plataformas sociais da circulação científica, como Academia.Edu e ResearchGate vem oferecido planos para que usuários tenham acesso às informações privilegiadas que não são disponibilizadas na versão gratuita, ou mesmo revistas Open Access que buscam sustentabilidade através do modelo de publicação Autor-paga e não Leitor-paga, como adotado pelas grandes editoras internacionais, ou ainda repositórios piradas que liberam o acesso à paywalls, como Lib-gen e Sci-Hub, mas não rompem com a lógica de acumulação de capital científico das editoras que cobram acesso ao material publicado em suas revistas.

Entendendo o conhecimento como um bem público, movimentos importantes em torno do Open Knowledge, e suas derivações em torno da abertura de dados, passou de uma causa de nicho em alguns países desenvolvidos para se tornar quase onipresente nas agendas políticas de governos em todo o mundo. Ciência Aberta, Educação Aberta, Inovação Aberta e Dados Governamentais Abertos são alguns dos rótulos que surgem inspiradas em ideias do "código aberto" (WILLINSKY, 2005), e desempenham um papel importante na condução da transparência (accountability), permitindo novas formas de participação e ação cívicas a partir de um discurso desenvolvimentista e progressista: o progresso da ciência e o avanço científico são afirmações constantes em torno da defesa dos movimentos abertos do conhecimento. Contudo, conforme aponta Sarita Albagli sobre Ciência Aberta (2014), é necessário entender o significado destes movimentos reconhecendo uma forte tensão entre a socialização e a privatização do conhecimento e da informação. 
Tais movimentos vão ao encontro da crescente demanda pela accountability, como elemento fundamental à democratização nos países ocidentais, ligados diretamente às noções de responsabilidade e transparência. Por sua vez, transparência vincula-se a um controle cognitivo através de um volume de dados sobre um ato e seu resultado, geralmente a posteriori do ocorrido. Segundo Gomes; Amorim; Almada (2018), esta tendência contemporânea de accountability e transparência exige a abertura de dados em uma parte e valoriza a função de gatekeepers, jornalistas e profissionais voltados para a produção da informação a partir destes dados abertos, bem como incentivo ao crescimento de organizações independentes, privadas e nãogovernamentais, voltadas para a distribuição de informação sobre governos, sistemas políticos, sistemas financeiros, etc. Contudo, quem controla a atuação esses agentes, que lucram em torno da produção da informação sobre os dados abertos?

Se de um lado há cada vez mais incentivo para a adesão os princípios da Ciência Aberta, por outro, as próprias entidades envolvidas neste processo são pouco transparentes ou até mesmo pouco visíveis. Por exemplo, pesquisadores financiados pelo Wellcome Trust têm utilizado um servidor de preprint aberto exclusivo da fundação, o Wellcome Open Research, ou pesquisadores financiados pela Fundação Bill e Melinda Gates que podem usar os servidores exclusivos de preprint da própria instituição, o Gates Open Research, alugado da plataforma F1000Research, ou Chan Zuckerberg Foundation que financia o servidor BioArxiv (DA SILVA, 2017). Há que troco estariam estas fundações interessadas em investir em dados científicos abertos? Enquanto os cientistas se agarram aos discursos ideológicos da ciência aberta e sua importância para o progresso científico, um mercado potencialmente lucrativo emerge no ecossistema científico global.

Como podemos verificar, não é possível simplesmente fazer a distinção dicotômica entre manutenção de poder ou resistências disruptivas que fazem parte do ecossistema científico. Trata-se de dinâmicas que possuem relação com uma agenda neoliberal, que tem como princípio a geração de valor em torno do conhecimento. Porém, quando se enfrenta crises econômicas como os países periféricos e semiperiféricos têm enfrentado nesses últimos anos, a reboque de crises financeiras ocasionadas nos países hegemônicos (ALMEIDA, 2012), este circuito investimento-conhecimento-valor é afetado, pois se torna impossível transformar conhecimento em dinheiro, sem ter dinheiro para investir em conhecimento. Por exemplo, uma pesquisa realizada pelo Laboratório de Investigação em Ciência, Inovação, Tecnologia e Educação (Cite-Lab), apontou para uma queda da produção científica que vem acompanhado quedas de investimento em Ciência, Tecnologia e Inovação no Brasil. Foram extraídos dados do Lattes de 14.609 professores bolsistas de produtividade de níveis 1 e 2, totalizando 1,2 milhões de 
produções em periódicos científicos. Como mostra nos gráficos abaixo, há uma queda de produção de 2014 até os dias atuais. ${ }^{13}$

Figura 2: Gráfico de produção de bolsistas de produtividade do Brasil.

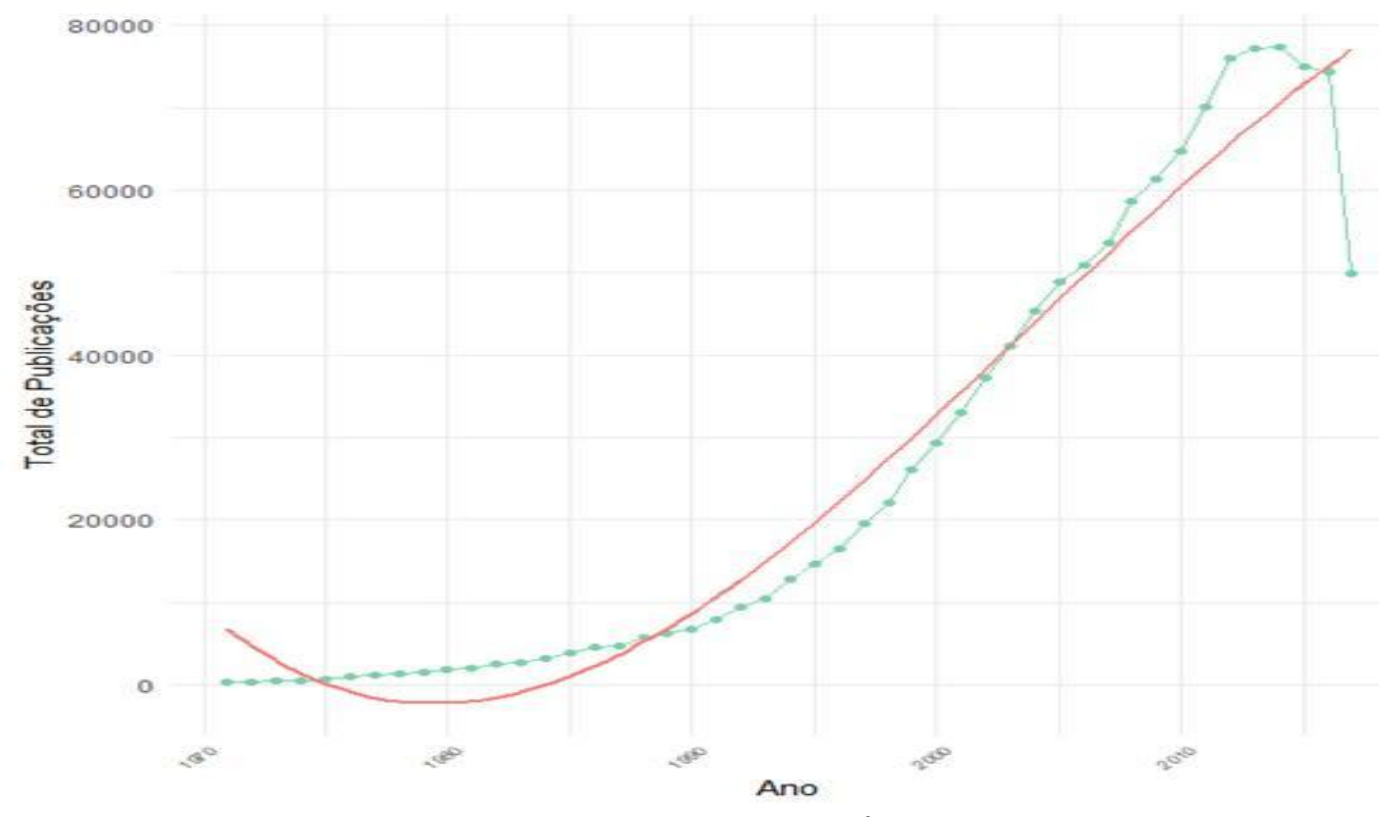

Fonte: Cite-Lab

Figura 3: Gráfico de orçamento CNPq 2001 a 2017

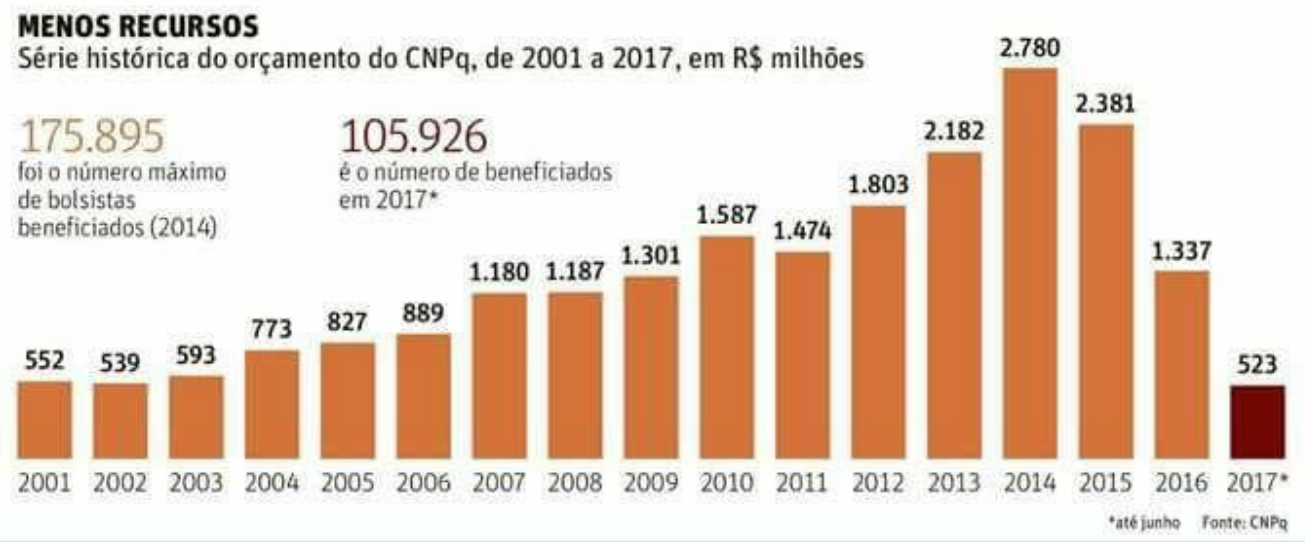

Fonte: Sant'anna, 2017

Ainda que não possa se retirar nenhuma conclusão direta entre investimento do governo em pesquisa e publicação dos pesquisadores, sobretudo em função de que o tempo do ciclo de produção de um artigo é de 1 a 2 anos, os gráficos acima ajudam ilustrar uma crise na ciência brasileira vem enfrentando. Desde 2014, o Brasil vem passando por uma grave crise política e econômica que acarretou cortes expressivos no orçamento disponível para ciência, tecnologia e inovação. No final de

\footnotetext{
${ }^{13}$ Como a extração de dados fora realizada anteriormente ao fechamento do ano de 2017, não é possível levar em consideração o ano atual, sendo necessário refazer o gráfico posteriormente para ter uma dimensão mais apurada da produção anual vigente.
} 
março de 2017, o orçamento de custeio e investimento do Ministério de Ciência, Tecnologia, Inovação e Comunicação (MCTIC) foi limitado a R\$ 3,2 bilhões neste ano, $44 \%$ menor do que o que havia sido estabelecido na lei orçamentária - sendo equivalente a menos da metade do orçamento empenhado de 2014, que foi de $\mathrm{R} \$ 7,3$ bilhões. Em períodos como este, torna-se evidente a necessidade de se avaliar os impactos dos investimentos realizados, a fim de que estas aplicações sejam voltadas, sobretudo para iniciativas promissoras.

Este assunto vem sendo discutido em importantes associações de classe como a Sociedade Brasileira para o Progresso da Ciência (SBPC) e a Academia Brasileira de Ciências ( $A B C)$. Existe uma percepção de que a ciência brasileira avançou bastante na quantidade de artigos, mas esses artigos não têm tido o impacto esperado. De acordo com Brito Cruz, "ao longo de sua história, a ciência feita no Brasil, na média, tem tido pouca repercussão internacional, atingindo $60 \%$ da média do impacto científico do restante do mundo"14. No entanto, não se trata apenas de uma mudança de cultura de pesquisa brasileira, mas também respostas diretas às práticas predatórias de invisibilização da ciência brasileira, como discutido anteriormente.

Diante de tanta discussão sobre o surgimento de revistas predatórias que vão surgindo (BARTHOLOMEW, 2014; XIA; HARMON, CONNOLLY, 2015; BEALL, 2016; BERGER; CIRASELLA, 2015; DADKHAH; BIANCIARDI, 2016, entre outros), com modelos de negócios altamente lucrativos - como as grandes editoras do oligopólio científico - , e listas duvidosas que categorizam como predatórias um conjunto de periódicos de acesso aberto e de países do Sul Global, nos resta perguntar: não seriam estas grandes editoras que controlam o mercado científico e invisibilizam a ciência dos países periféricos e semi-periféricos as maiores predadoras nesse ecossistema científico global?

\section{Considerações finais}

Este trabalho teve como proposta oferecer uma análise de conjuntura sobre o ecossistema científico global e suas especificidades e particularidades nacionais. Tomamos como ponto de partida uma compreensão de que o ecossistema científico é um espaço dinâmico e complexo, com organismos vivos interdependentes e atuam de maneira interconectada, se afetam mutuamente e são afetados pelo atores humanos e não-humanos do ambiente do qual se adaptam e nos quais as fronteiras de diferentes esferas da vida são permeáveis. Para entender o ecossistema científico, é necessário olhar não apenas para as partes, mas o todo. Ou seja, é necessário compreender tanto as particularidades de cada circuito, mas também as fronteiras permeáveis entre todo o conjunto de circuitos nacionais em uma escala global.

Levando em consideração que a Ciência é uma área estratégica para o desenvolvimento econômico e para a soberania dos países, é necessário

14 http://agencia.fapesp.br/pesquisa_de_qualidade_nao_de_quantidade/17608/ 
entender quais são as macroestruturas que atuam em uma esfera global. Portanto, foi necessário entender como se configura a geopolítica do conhecimento e como suas práticas atuam sobre o cenário nacional. Neste panorama, o conhecimento científico, na junção com um projeto hegemônico neoliberal, tem sido utilizado como aparelho ideológico e instrumento de dominação e poder na sociedade do conhecimento, do qual o oligopólio científico domina os circuitos tradicionais da ciência através de um conjunto de seis grandes editoras científicas. Estas editoras não apenas monopolizam o mercado científico, através de discursos de legitimação, qualidade e visibilidade, monetizando o conhecimento, como também influenciam as políticas científicas de vários países, através da consagração de indicadores de avaliação da ciência desenvolvidos pelas empresas e a partir de matrizes de suas próprias bases.

Estes indicadores vêm pautando as políticas científicas no Brasil, em diferentes áreas do conhecimento, instaurado por uma cultura da citação e a maré de métricas que assolou o sistema científico global. Que adotam esses indicadores como avaliação de área, servindo como mordomos aos interesses dessas empresas que dominam o mercado editorial. Contudo, a relação entre a universidade brasileira e a agenda neoliberal é estreita e não se limita apenas ao oligopólio científico. Também diz respeito às políticas públicas que foram adotadas no país, e continuam sendo, garantindo a preponderância do monopólio de interesses financeiros sobre a educação, a pesquisa e a inovação de alguns países sobre os demais, infringindo os próprios interesses nacionais e sua soberania. Esta agenda neoliberal que tem sido $o$ propulsor de diversos ataques que a universidade pública e o ensino superior gratuito têm sofrido nestes últimos dois anos, intensificado após o golpe de 2016 e que tem afetado a produção de conhecimento científico e tecnológico no Brasil.

Percebemos que o comportamento dos pesquisadores é influenciado a partir de políticas científicas que estabelece as diretrizes da área, e que incidem sobre a forma do pesquisador comunicar sua ciência, seja pela disseminação, seja pela divulgação científica. De um lado, é necessário que a comunidade científica reporte para os agentes financiadores estatais apresentando o resultado dos investimentos realizados nas pesquisas e por outro, é necessário que estes resultados dialoguem com a sociedade e atendam as demandas e necessidades sociais, através de desenvolvimento de produtos, oferta de serviços e outras ferramentas tecnológicas de inovação que possibilitaram modificações significativas na vida cotidiana. Em ambas as esferas de comunicação científica, os pesquisadores buscam construir uma reputação junto aos seus pares, ao passo que concorre ao espaço de legitimação e de influência na comunidade acadêmica nacional e/ou internacional através de uma maior visibilidade de sua produção.

Nesses espaços de construção de reputação através da visibilidade, o uso de mídias sociais tem sido um importante instrumento de comunicar a ciência, ajudando a disseminar os achados da pesquisa para um público amplo. Esta é uma prática que vem crescendo na comunidade científica e reconfigurando o trabalho acadêmico na sociedade midiatizada. No 
entanto, estes mesmos espaços de circulação de conteúdos científicos também são disputados por outros atores, legitimados ou não pela ciência. Nestes espaços, disputas de poder e de visibilidade em torno da discussão sobre ciência têm sido ocupado por alguns atores e que também são refletidos no próprio cenário político brasileiro.

Esta reflexão, portanto, busca entender que o ecossistema científico é um espaço no qual possui disputas de poder, agendas neoliberais e reflexos de políticas nacionais que agem sobre um conjunto de atores diversos, com interesses e particularidades próprias. Não se trata apenas em denunciar os circuitos hegemônicos nos quais a ciência moderna foi balizada, suas consequências nos panoramas locais, e as disputas que se formam nesses cenários nacionais nas redes sociais e nas políticas institucionais, mas também entender como esse conjunto de atores e sujeitos se relacionam no ecossistema científico global.

\section{Referências}

ALBAGLI, Sarita. Divulgação científica: informação científica para cidadania. Ciência da informação, v. 25, n. 3, p. 396-404, set./dez. 1996 Disponível em: http://revista.ibict.br/ciinf/article/view/639/643. Acesso em: 01 maio 2018.

ALBAGLI, Sarita. Ciência Aberta em questão. In: SEMINÁRIO INTERNACIONAL CIÊNCIA ABERTA, QUESTÕES ABERTAS, Rio de Janeiro, 2014. [Anais...] Rio de Janeiro: Liinc; IBICT; OKF; Unirio, 2014. Disponível em: http://www.cienciaaberta.net/encontro2014/. Acesso em: 01 maio 2018.

ALMEIDA, Paulo Roberto. Relações internacionais e política externa do Brasil: a diplomacia brasileira no contexto da globalização. Rio de Janeiro: Grupo Gen-LTC, 2012.

BARTHOLOMEW, Robert E. Science for sale: the rise of predatory journals. Journal of the Royal Society of Medicine, New York, v. 107, n. 10, pp. p. 384-385, Out. 2014.

BEALL, Jeffrey. Predatory journals: Ban predators from the scientific record. Nature, v. 534, n. 7607, p. 326-326, 2016.

BENNETT, Karen. The "butler" syndrome: academic culture on the semiperiphery. Revista Canaria de Estudios Ingleses, n.69, p.155-171 Dec. $2014 . \quad$ Disponível em: https://riull.ull.es/xmlui/bitstream/handle/915/4547/RCEI 69 (2014) 09. pdf. Acesso em: 01 maio 2018.

BERGER, Monica; CIRASELLA, Jill. Beyond Beall's list: better understanding predatory publishers. College \& research libraries news, v. 76, n. 3, p. 132-135, 2015.

BOULDING, Kenneth E. General systems theory-the skeleton of science. Management science, Catonsville, v. 2, n. 3, p. 197-208, 1956. 
BRINN, Tony; JONES, Michael John. Editorial boards in accounting: The power and the glory. Accounting Forum, v. 31, n. 1, p.1-25, March 2007.

BUENO, W.C. Jornalismo científico no Brasil: compromissos de uma prática dependente. 1984. 364p. Tese - Escola de Comunicações e Artes, Universidade de São Paulo, São Paulo, 1984.

BURCH, Sally. Sociedade da informação/sociedade do conhecimento. Desafios de Palavras: Enfoques Multiculturais sobre as Sociedades da Informação. São Paulo: C\&F editions, 2005.

CASSIOLATO, José Eduardo et al. Indicadores de Inovação: uma análise crítica para os BRICS. Rio de Janeiro: RedeSist-Relatório de Pesquisa, 2008.

CONFRARIA, Hugo; GODINHO, Manuel Mira; WANG, Lili. Determinants of citation impact: A comparative analysis of the Global South versus the Global North. Research Policy, v. 46, n. 1, p. 265-279, 2017.

COOKSON, R. Reed Elsevier to rename itself RELX Group. Financial Times, London, 26 Feb. 2015.2 Disponível em: https://www.ft.com/content/4be90dbe-bd97-11e4-9d09-00144feab7de.

Acesso em: 23 Sept. 2015.

COSTA, R. Wikipédia é criticada por parceria com a Elsevier. Tecnomundo, 18 set. 2015. Disponível em: https://www.tecmundo.com.br/wikipedia/86703-wikipedia-criticadaparceria-elsevier.htm. Acesso em: 01 maio 2018.

DADKHAH, Mehdi; BIANCIARDI, Giorgio. Ranking predatory journals: solve the problem instead of removing it!. Advanced pharmaceutical bulletin, Tabriz, v. 6, n. 1, p. 1-4, 2016.

DA SILVA, Jaime A. Teixeira. The preprint debate: What are the issues?. Medical Journal Armed Forces India, Pune (Índia), v. 74, n. 2, p. 162-164, April 2018.

DHANANI, Alpa et al. Editorial boards of accounting journals: gender diversity and internationalisation. Accounting, Auditing \& Accountability Journal, v. 30, n. 5, p. 1008-1040, 2017.

DUARTE, Newton. Sociedade do conhecimento ou sociedade das ilusões. Campinas: Autores Associados, 2003.

ETZKOWITZ, HENRY; ZHOU, CHUNYAN. Hélice Tríplice: inovação e empreendedorismo universidade-indústria-governo. Estudos Avançados, v. 31, n. 90, p. 23-48, 2017.

FIGUEIREDO, Ireni Marilene Zago. Os projetos financiados pelo Banco Mundial para o ensino fundamental no Brasil. Educação \& Sociedade, v. 30, n. 109, 2009.

FREY, Klaus. Políticas públicas: um debate conceitual e reflexões referentes à prática da análise de políticas públicas no Brasil. Planejamento e políticas públicas, n. 21, 2009. 
GARFIELD, Eugene. The use of journal impact factors and citation analysis for evaluation of science. In: ANNUAL MEETING OF THE COUNCIL OF BIOLOGY EDITORS, 41, 1998. Salt Lake City, UT. 1998.

GOMES, W.; AMORIM, P. K.; ALMADA, M. P. Novos desafios para a ideia de transparência pública. E-Compós, Brasília, v. 21, n. 2, p.1-21, maio/ago. 2018.

GUIMARÃEs, E. A. A Política Científica e Tecnológica e as Necessidades do Setor Produtivo. Rio de Janeiro: Instituto de Economia Industrial, Universidade Federal do Rio de Janeiro, 1993.

HEYMAN, Tom; MOORS, Pieter; STORMS, Gert. On the cost of knowledge: Evaluating the boycott against Elsevier. Frontiers in Research Metrics and Analytics, v. 1, n. 7, 2016.

HICKS, Diana et al. The Leiden Manifesto for research metrics. Nature, v. 520, n. 7548, p. 429, 2015.

HOPKINS, Terence K.; WALLERSTEIN, Immanuel Maurice. World-systems analysis: Theory and methodology. Sage, 1982.

KUHN, Thomas S.; HAWKINS, David. The structure of scientific revolutions. American Journal of Physics, v. 31, n. 7, p. 554-555, 1963.

LARIVIĖRE, Vincent; HAUSTEIN, Stefanie; MONGEON, Philippe. The oligopoly of academic publishers in the digital era. PloS one, v. 10, n. 6, p. e0127502, 2015.

LASTRES, Helena MM; ALBAGLI, Sarita. Informação e globalização na era do conhecimento. Rio de Janeiro: Campus, p. 163, 1999.

LEHER, R. Da ideologia do desenvolvimento à ideologia da globalização: a educação como estratégia do Banco Mundial para "alívio" da pobreza. São Paulo: FEUSP, 1998.Tese (Doutorado em Educação) - USP.

LUUKKONEN, Terttu. Invited review article: Bibliometrics and evaluation of research performance. Annals of medicine, v. 22, n. 3, p. 145-150, 1990.

MAY, R. M. \& HALDANE, A. G. Systemic risk in banking ecosystems. Nature 469, 351-355, 2011.

MAZLOUMIAN, Amin et al. Global multi-level analysis of the 'Scientific Food Web'. Scientific reports, v. 3, p. 1167, 2013.

MEADOWS, Arthur Jack. A comunicação científica. Brasília: Briquet de Lemos/Livros, 1999. 268 p.

MERTON, Robert K. The sociology of science: Theoretical and empirical investigations. University of Chicago press, 1973.

NASSI-CALÒ, Lilian. Open access as a sustainable alternative to scholarly communication. Blog Scielo, 2012.

OLIVEIRA, D.A.; FONSECA, M. O Banco Mundial e as políticas de formação docente: a centralidade da educação básica. In: HIDALGO, A.M. et al. 
(Org.) Educação e Estado: as mudanças nos sistemas de ensino do Brasil e Paraná na década de 90. Londrina: UEL, 2001.

OLIVEIRA, T. Midiatização da Ciência: Reconfiguração do paradigma da comunicação científica e do trabalho acadêmico na era digital. Matrizes, v. 12, n.3, 2018 (No prelo)

PONTE, Diego; MIERZEJEWSKA, Bozena I.; KLEIN, Stefan. The transformation of the academic publishing market: multiple perspectives on innovation. Electronic Markets, v. 27, n. 2, p. 97-100, 2017.

RÀFOLS, Ismael; MOLAS-GALLART, Jordi. A call for inclusive indicators that explore research activities in "peripheral" topics and developing countries. Impact of Social Sciences Blog, 2016.

RUOTSALAINEN, Juho; HEINONEN, Sirkka. Media ecology and the future ecosystemic society. European Journal of Futures Research, v. 3, n. 1, p. 9, 2015.

SANTOS, Boaventura de Sousa. Para além do pensamento abissal: das linhas globais a uma ecologia de saberes. Novos estudos-CEBRAP, n. 79, p. 71-94, 2007.

SMALDINO, Paul E.; MCELREATH, Richard. The natural selection of bad science. Royal Society Open Science, v. 3, n. 9, p. 160384, 2016.

TAYLOR, Mike (16 January 2011). "Academic publishers have become the enemies of science". The Guardian, 2011.

THELWALL, Michael. Web indicators for research evaluation: $A$ practical guide. San Rafael, CA: Morgan \& Claypool.

VERBIK, Line. The international branch campus: Models and trends. International Higher Education, n. 46, 2015.

WAGNER, Caroline S.; WONG, Shing Kit. Unseen science? Representation of BRICs in global science. Scientometrics, v. 90, n. 3, p. 1001-1013, 2012.

WILKINS, Stephen; HUISMAN, Jeroen. The international branch campus as transnational strategy in higher education. Higher Education, v. 64, n. 5, p. 627-645, 2012.

WILLINSKY, J. The unacknowledged convergence of open source, open access, and open science. First Monday, 10(8), 2005.

WOUTERS, Paul et al. The metric tide: Literature review (Supplementary report I to the independent review of the role of metrics in research assessment and management). The Higher Education Funding Council for England, v. 10, 2015.

XIA, Jingfeng et al. Who publishes in "predatory" journals?. Journal of the Association for Information Science and Technology, v. 66, n. 7, p. 14061417, 2015. 